\title{
AN ASSESSMENT OF USER PREFERENCE IN ARTIFICIAL PATHWAY LIGHTING IN URBAN PARKS; \\ Cases from Greater Colombo region
}

\author{
WICKREMASINGHE L.L.S. ${ }^{1} \&$ HETTIARACHCHI A.A. ${ }^{2}$ \\ 1, 2University of Moratuwa, Katubedda, Sri Lanka \\ 1lashaniwickremasinghe@gmail.com,2anishkah@uom.lk
}

\begin{abstract}
Urban parks are critical in converting cities to liveable spaces, where artificial lighting directly affects the users' night-time experience. This study explores the urban park users' preferences in artificial pathway lighting, through their subjective responses towards Brightness, Correlated Colour Temperature (CCT), and luminaires of the existing lighting design, at four popular urban parks in Colombo. The reasons for the said preferences were investigated under three overarching themes: perceived safety, perceived quality of light, and restorative experience. A mixed methods approach was employed for data collection, where questionnaires were used together with measurements, in-situ observations, and photographic analysis for better understanding. The user preferences were found to be directly associated with their perception of the lit environment. The existing brightness levels are insufficient for majority of the users and has affected their perception of safety. The poor selection and placement of luminaires have negatively affected the lighting quality, while the positive effect on the users' restorative experience has induced a higher preference towards the CCT of the light sources. The results revealed that the majority of the users opted for changes in the current lighting design, indicating that the user needs and requirements are not effectively addressed in this regard.
\end{abstract}

Keywords: User Preference, Outdoor Artificial Lighting, Pathway Lighting, Urban Parks

\section{Introduction}

Light is a main attribute that aides the human visual process, through which they perceive and use a space. The presence of light, its colour/ warmth and its intensity have physiological as well as psychological effects on human beings, and is therefore, an indispensable environmental input (Unver, 2009). Artificial outdoor lighting plays an important role in enhancing the quality of urban public spaces during dark hours and directly affects the users' night-time experience. Not only is it used as a means of safety and security, but also improves the aesthetic quality of urban spaces at night. It can be considered as a significant element of urban life. Majority of the users are unaware of the physiological and psychological effects of artificial lighting. Nevertheless, it is important to consider those aspects when developing a lighting design to ensure both public health and durability of the design.

Urban Parks play a critical role in converting cities to liveable spaces. They can be considered important as well as indispensable parts of city space, which have contributed to the organization and definition of space, sometimes even as landmarks. According to previous studies, it is evident that when well-designed, these civic spaces can stimulate economic growth, improve public health and wellbeing, and encourage human - human as well human - nature interactions.

Artificial lighting is a major contributing factor towards the successful design of urban parks. Since the outdoor lighting condition is directly linked to the user experience, it is important to explore the 
needs and preferences of all user groups and address them through the lighting design. However, in most cases lighting techniques are chosen based on upfront cost rather than considering the lighting quality, environmental impact, energy efficiency or user preferences. In many existing lighting designs standardized solutions have been given, which are contrary to the user requirements (Unver, 2009).

\section{Research objectives}

The purpose of this study is to explore the parameters of users' preference related to artificial pathway lighting of urban parks. Further it is attempted to assess the extent to which the user needs have been addressed through the current lighting designs with reference to a selected urban park in Colombo. The findings of this study will contribute towards enhancing night-time experience of urban park users.

\section{Literature Review}

\subsection{ARTIFICIAL OUTDOOR LIGHTING}

Artificial Outdoor lighting is used for a variety of purposes in the modern society. It plays an important role in providing functional levels of visual accessibility, and perceived safety during the dark hours (Rahm \& Johansson, 2018) and thereby improves mobility. Apart from general illumination, lighting composition can also be used for aesthetical purposes by creating shapes and emotional responses, and thereby gives a sense of place to an area. It is used to emphasize features of architectural or historic significance, and to light parks and gardens (Silva, 2011). Lighting that is responsive to the architecture of a space conveys meaning and contributes towards the users' understanding of the space (Rea, 2000). As Lindh (2012) states, lighting can be used to emphasize or minimize what people see. It can be used to highlight an interesting element as well as a specific function in the space. However, artificial lighting generates both environmental and economic costs. This can be minimized by effectively addressing both technical and human aspects when updating existing outdoor lighting applications in terms of design and energy efficiency (Rahm \& Johansson, 2018).

The public use of urban spaces is influenced by a variety of urban qualities. These include not only large -scale structures, but also small-scale elements in the urban context such as urban greenery, adequate lighting, etc. Therefore, it is important to be fully aware of how elements of such small-scale affect and improve the user experience (Patching, Rahm, Jansson, \& Johansson, 2017). Artificial lighting is a major contributing factor towards the successful design of urban parks, which in turn can enrich the park's social, health, economic and environmental benefits. The US National Park Service Management Policies (2006) instructs the authorities to limit artificial lighting to areas where security, basic human safety, and cultural requirements must be met, such as pathways, amphitheaters and comfort stations (restrooms, sinks), and thereby preserve the parks' natural lighting condition to the greatest extent possible.

\subsection{PATHWAY LIGHTING IN URBAN PARKS}

Among all park facilities, park pathways are more significantly related to physical activity, and lighting is an important attribute that should be carefully considered during its design (Zhai \& Baran, 2016).Pathway lighting is critically important for people's use of urban parks. According to Silva (2011), the use of artificial lighting to highlight pathways/ walkways helps people navigate safely within the premises, and it may also define other elements bordering them, such as gardens and waterscapes.

The Guidelines for Outdoor Lighting in Urban Star Parks, adapted by the Royal Astronomical Society of Canada - RASC (2016) states that even though pathway lighting provides visibility which is necessary for navigation, excessive illumination prevents the users from seeing off the path for situational awareness. According to Rea (2000), important criteria for pathway/ bikeway lighting are vertical illuminance, colour appearance, shadows, resource/ task/ eye geometry, peripheral detection, facial recognition and obstacle detection, glare (direct and indirect), and light pollution/trespass. As clarified by Rea (2000) the standard horizontal illumination is 50 lux, while the standard vertical illumination is 30 lux.

\subsection{USER PERCEPTIONS AND PREFERENCES ON ARTIFICIAL LIGHTING}

Rahm \& Johansson (2018) state that it is important to consider human aspects as well as technical considerations during this process, in order to implement pedestrian friendly, energy efficient lighting solutions, which are adapted to user needs. However, it is important to identify and prioritize which human 
needs are to be served through the lighting design after a careful thought process, to avoid conflict (Rea, 2000).

According to the US National Park Service (NPS) Management Policies (2006), the park users' experiences and outdoor lighting conditions are closely linked. However, there is a lack of understanding about the user preferences and the respective reasons, which negatively affects the initiatives taken by the respective authorities to create a quality night-time experience for the visitors (Smith \& Hallo, 2019). Schiffman (2000) states that the average person does not often consciously consider or understand lighting conditions that enhance or degrade their ability to see, due to the involuntary nature of the human visual process. As the majority of people are exposed to poor lighting conditions and light pollution on a daily basis, they are not aware of their implications unless they get a chance for comparison or are otherwise knowledgeable about good lighting practices (Smith \& Hallo, 2019).

\subsubsection{Brightness}

Schiffman (2000) describes brightness as being directly (but not simply) related to the intensity of light, where more intense light appears whiter, and decreasing intensity leads to a darker appearance. He further states that the brightness of a region depends on the intensity of its background. As Rea (2000) states, a luminaire considered bright by one person, may not be so to another, due to the subjective nature of a lighting scene. As stated by Nikunen \& Korpela (2009) perceived brightness may also differ based on what is illuminated. According to previous research it has been found that brightness perception depends on the light source (Rea, Bullough, \& Akashi, 2009) The height of light fixtures along urban footpaths have also been found to affect the perceived brightness (Johansson, Rosen, \& Kuller, 2010).

Brightness affects the distance and spaciousness in spaces (Lindh, 2012). The perceived brightness may also affect the restorative experience and it is also possible that the preference and the positive attitudes towards the restorative environments makes it appear brighter (Nikunen \& Korpela, 2009).

\subsubsection{Correlated Colour Temperature (CCT)}

In addition to brightness, the CCT of a light source also affects user perceptions and preferences. Rea (2000) states that the colour appearance of a light source which affects the visibility and aesthetics of a space, is an important technical factor that should be considered when evaluating an exterior lighting system. Although colour perception and differentiation are based on the wavelength compositions of light sources, they can be considered as subjective phenomenal experiences which have profound aesthetic and emotional effects on man (Schiffman, 2000).

\subsubsection{Luminaire type and design}

The positioning/ arrangement of luminaires as well as their relationship with one another affects the appearance of a space. The location and size of the poles, and the size of the equipment helps in creating a lighting hierarchy. It is important that the lighting coordinates with the architecture and enhances the spatial design. This can help give an identity to the space. Careful positioning of luminaires can provide visual cues that assist occupant orientation, while in some instances lighting equipment may interfere with the view of a natural landscape or a carefully designed space and thereby create 'visual clutter' (Rea, 2000).

\subsection{REASONS FOR OUTDOOR LIGHTING PREFERENCES}

Kaplan \& Kaplan (1989) describe the term 'preference' as an expression of underlying human needs and state that it is closely linked to their basic concerns. Veitch and Newsham (1996) further strengthens the definition by describing 'preference' as what people consider better in terms of satisfaction and comfort when comparing one environment with another. According to Kaplan \& Kaplan (1989), people prefer settings where it is easiest to extract information which in turn helps them function effectively. preference is closely related to perception, where the measurement of preference allows an examination of the perceptual process. The perceptual quality of the urban environment, which is based on the perception of the user community, plays an important role in linking the physical characteristics of the environment with people's preferences (Ernawati, Surjono, \& Sudarmo, 2018). 


\subsubsection{Perceived safety}

It has been found that the distribution of light influences attention and feeling of safety (Lindh, 2012), as it helps in identifying and illuminating environmental features which compromise safety. However, since both psychology and vision contribute towards safety and security, it is a challenging design criterion for outdoor lighting (Rea, 2000). From their user survey Luo et al. (2013) found that people considered pedestrian way lighting important in regard to movement and safety. Taking their study, a bit further from just facial recognition, Fotios, Yang and Cheal (2013) recognizes the ability to make accurate judgements about the intent of other pedestrians, also as one basis of personal safety. Although greater luminance or higher illuminance is often associated with the surrounding being safer, poorly directed light can reduce visibility and thereby reduce safety and security (Rea, 2000).

\subsubsection{Perceived quality of lighting}

There is no clear definition as to what parameters create good lighting quality. However, the majority believe that illuminance, luminance, luminance distribution, uniformity, glare control, spectral power distribution (SPD), and flicker rate are important elements of the lit environment. Previous studies suggest that these factors affect behavioral outcomes such as visual comfort, task performance, preferences, and wellbeing (Veitch \& Newsham, 1996). Veitch and Newsham (1996) has given a behavior-based definition for lighting quality, which defines it as the degree to which the lit environment supports, visual performance, post-visual performance, social interaction and communication, mood state (happiness, alertness, satisfaction and preference), health and safety, as well as the aesthetic judgements of the people who use the space. According to Allan, Hansen, Isoardi, \& Smith, (2019), lighting quality depends on the purpose and the user of the space. In other words, it depends on the interaction between lighting, place, and person.

\subsubsection{Restorative experience}

Lighting helps create the visual image of the urban nightscape, together with its surrounding surfaces, shapes, and spaces, and therefore might have a considerable effect on the restorative experience. If explained further, lighting can either enhance the restorative effect by focusing our attention to the positive restorative features or weaken the effect by highlighting the negative restorative features (Nikunen \& Korpela, 2009). According to Lindh (2012), light distribution, colour and light level plays an important role in spatial experience, where the pattern and direction of light affect size and shape. The lighting design can affect the observer's view and understanding of a space as well as their orientation within it, by manipulating architectural features and spatial conditions in order to expose, tone down, make a contrast, follow, or accentuate.

\subsection{THEORETICAL FRAMEWORK}

There are many parameters of artificial lighting which should be carefully considered to achieve a successful lighting design. The perception of these parameters, like any other element in the urban form, differs with an individual's life cycle circumstances and personal characteristics. Therefore, the evaluation of the lit environment differs from one person to another. The following table summarizes the artificial lighting parameters affecting human perception and preference and the aspects of evaluation which have been assessed under various scenarios in previous research.

Shown in colour in the below table are the artificial lighting parameters and the aspects of evaluation chosen for the study. These components were selected based on the appropriateness in terms of pathway lighting, and the practicality of assessing them within the chosen urban parks. Through the integration of these components the theoretical framework of this study was formulated as given in Figure 1. 


\begin{tabular}{|c|c|c|c|c|c|}
\hline & $\begin{array}{l}\text { Smith \& Hallo, } \\
2019\end{array}$ & $\begin{array}{c}\text { Rahm \& } \\
\text { Johansson, } \\
2018 \\
\end{array}$ & $\begin{array}{c}\text { Rahm \& } \\
\text { Johansson, } \\
2016\end{array}$ & $\begin{array}{c}\text { Fotios, Unwin \& } \\
\text { Farral, } 2014\end{array}$ & $\begin{array}{l}\text { Lindh, } \\
2012\end{array}$ \\
\hline \multirow{3}{*}{$\begin{array}{l}\text { Parameters } \\
\text { Perception \& } \\
\text { Preference }\end{array}$} & CCT & $\begin{array}{l}\text { Spectral Power } \\
\text { Distribution } \\
\text { (SPD) }\end{array}$ & Brightness & Illumination & $\begin{array}{l}\text { Illumination/ } \\
\text { Brightness }\end{array}$ \\
\hline & Brightness & CCT & $\begin{array}{l}\text { Acuity \& } \\
\text { Contrast }\end{array}$ & SPD & $\begin{array}{l}\text { Light } \\
\text { Distribution }\end{array}$ \\
\hline & $\begin{array}{l}\text { Lighting } \\
\text { characteristics }\end{array}$ & Glare & $\begin{array}{l}\text { Colour } \\
\text { Identification }\end{array}$ & & \\
\hline \multirow[t]{4}{*}{ Evaluation } & Safety & $\begin{array}{l}\text { Facial } \\
\text { Recognition }\end{array}$ & $\begin{array}{l}\text { Facial } \\
\text { Recognition }\end{array}$ & $\begin{array}{l}\text { Reassurance } \\
\text { Perceived } \\
\text { Safety/ Fear of } \\
\text { Crime }\end{array}$ & $\begin{array}{l}\text { Experience of } \\
\text { Space - } \\
\text { enclosure, } \\
\text { size/ depth }\end{array}$ \\
\hline & Experience & $\begin{array}{l}\text { Obstacle } \\
\text { Detection }\end{array}$ & $\begin{array}{l}\text { Obstacle } \\
\text { Detection }\end{array}$ & & Safety \\
\hline & & $\begin{array}{l}\text { Quality of } \\
\text { Lighting }\end{array}$ & & & \\
\hline & & Emotional State & & & \\
\hline Behaviour & & Walking Speed & & & \\
\hline
\end{tabular}

Table 1: Selection of parameters and aspects of study (Source: Author)

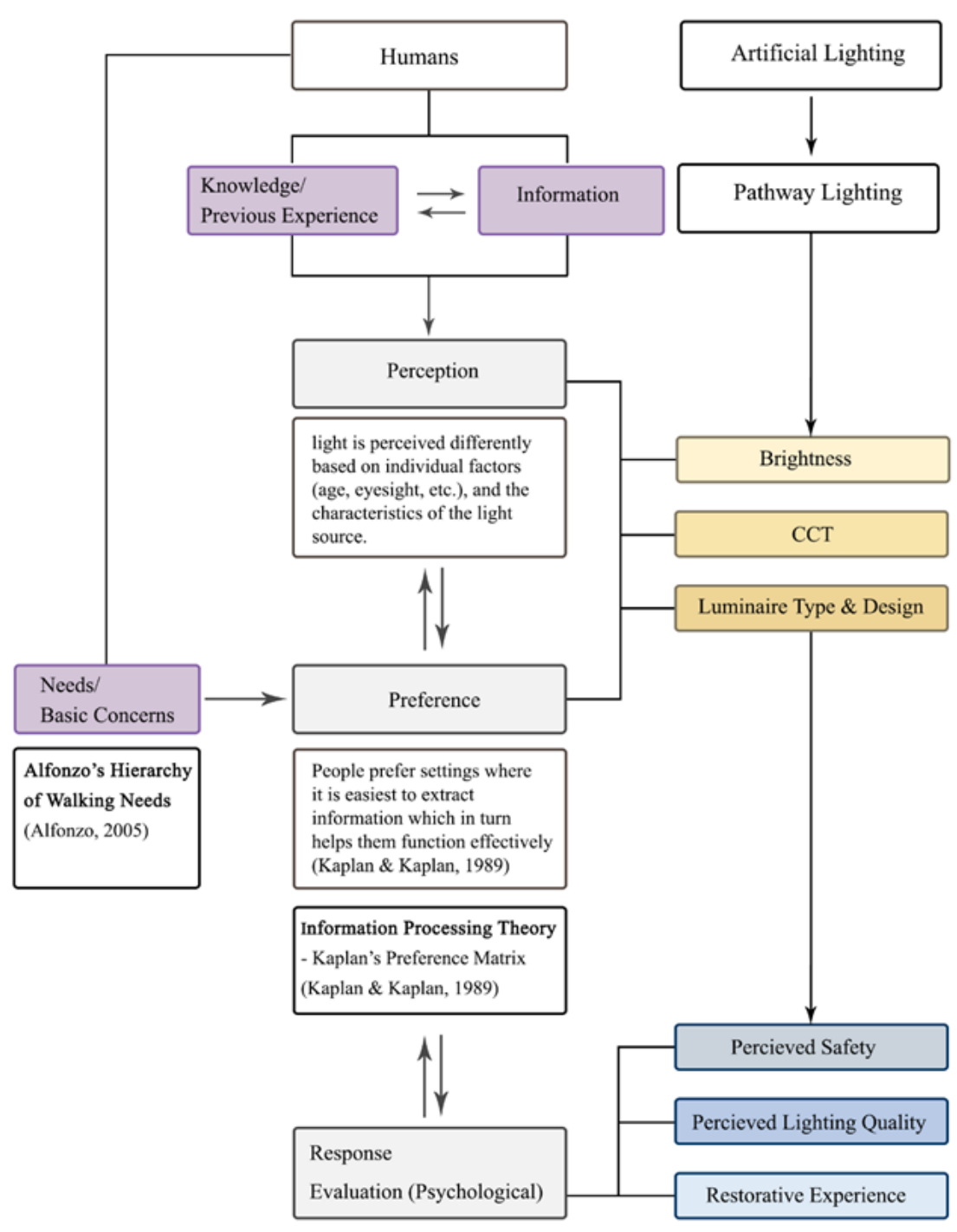

Figure 1: Theoretical framework of the study

(Source: Author) 


\section{Research Methodology}

Having identified the need to address user needs and preferences in the lighting design of urban parks, the main aim of this study is to evaluate the user preferences for artificial lighting in urban parks and the respective reasons.

A mixed methods approach was adapted for the study under two main steps, namely, the literature review survey and the case study survey. The literature review was carried out as the first step, where secondary data was gathered through exiting research pertaining to the fields relevant for this study. Photometric qualities and parameters of artificial lighting were assessed to identify the most significant qualities/ parameters which has the most effect in relation to the night time use of pathways, along with the most prominent reasons for preference. Accordingly, the user preferences were explored under the parameters: brightness, CCT, and Luminaire type/ design, whereas the reasons for their preferences were evaluated under perceived safety, perceived quality of light, and the emotional state/ restorative experience via a questionnaire survey adopting a 5-point Likert scale on a negative to positive continuum.

Four urban parks within the Greater Colombo region, were selected based on three main criteria namely: accessibility during dark hours, significant amount of night-time activity and the variety in artificial lighting of pathways (techniques and luminaires), through observations done prior to the study. Convenience Sampling - a non-probability sampling method was used, where park users were selected based on their availability and willingness to participate in the data collection process. The study sample was gender unbiased and comprised of 10 participants ( 5 males and 5 females) from each of the 4 parks, with the total being 40 park users ( 20 males and 20 females).

Questionnaires were distributed among park users to investigate their preferences towards the existing pathway lighting conditions. On site observations were conducted to identify how the pathways were being utilized, while illumination levels were measured to support the comparison of brightness. The analysis of the collected data helped in extracting a conclusive result on the user preferences related to artificial lighting of pathways in urban parks. The Covid19 pandemic situation was a main constraint throughout the course of the study, as public interactions and social gatherings were banned for around four months by the government. It mostly affected the data collection procedure as there were limitations in conducting public surveys. As a result, the sample size was limited to a few participants.

The personal opinions of the park users were cross referenced with the measured illumination levels of pathways and the IESNA lighting design guidelines, when analysing the user preferences for brightness.

\section{Findings and Discussion}

The respondents' personal preferences for pathway lighting under the parameters: brightness, CCT and luminaire type/ design in all four case study locations can be collectively represented as follows. (Figure 2).

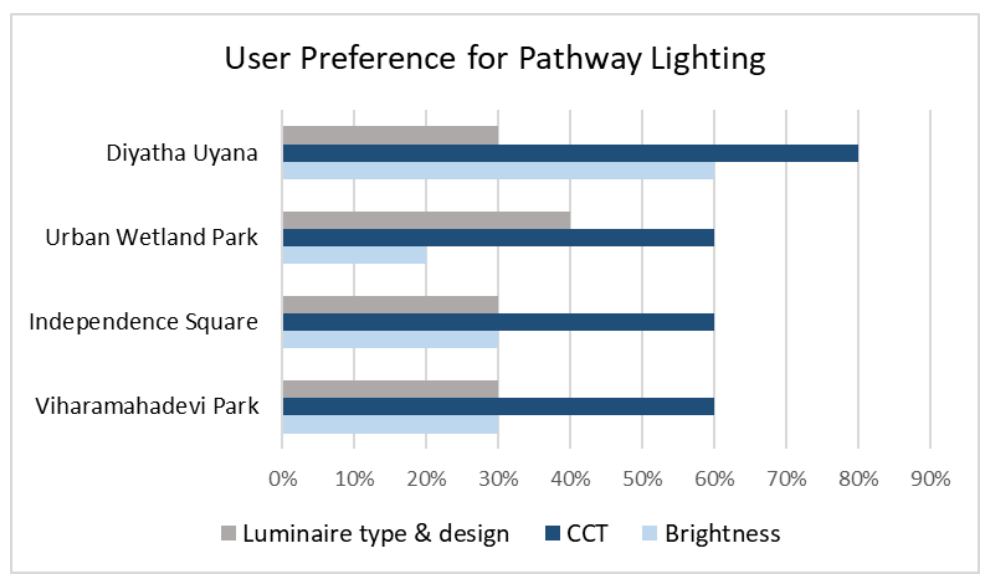

Figure 2: User preferences for pathway lighting (Source: Author) 
As measured by the digital lux meter, the horizontal illuminance of the pathways at all four urban parks were below 10 lux, whereas the IESNA recommends a horizontal illuminance of 50 lux. Apart from Diyatha Uyana, where $60 \%$ of the users prefer the existing level of brightness, the brightness levels of pathways at the other three urban parks do not satisfy more than $30 \%$ of its users. Majority of the users of Viharamahadevi Park, Independence Square, and the Urban Wetland Park prefer the illumination to be increased than the current level, further implying that the exiting illumination levels of pathways are insufficient. The preference for the luminaires used for pathway lighting was also found to be low, as less than $40 \%$ of the users prefer the exiting luminaire types and designs at each park. However, majority of the users at each urban park prefer the existing CCT of the light sources, as it creates a calm and relaxing ambience.

The reasons for the above preferences, evaluated under three overarching themes: perceived safety, perceived quality of light and the restorative experience can be represented as follows (Figure 3).

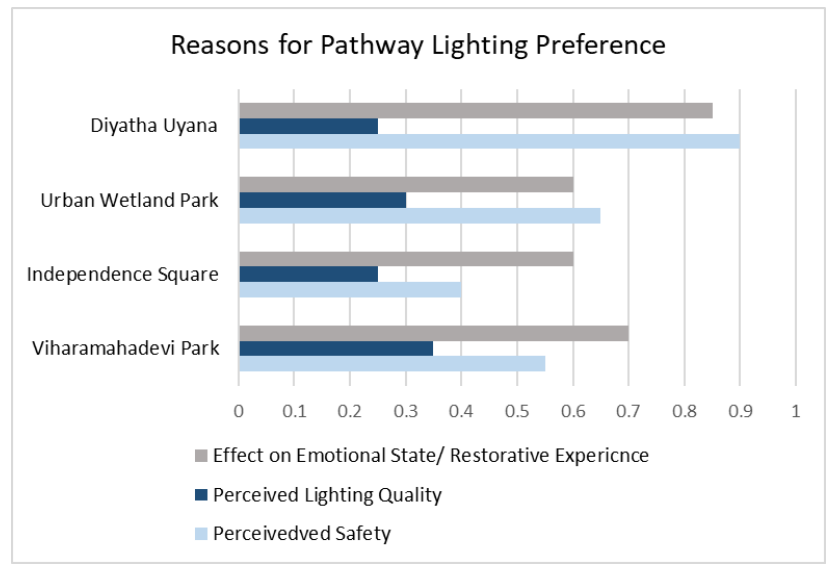

Figure 3: Reasons for pathway lighting preferences (Source: Author)

Except in Diyatha Uyana, where $90 \%$ of the participants have rated the pathways as safe for use, less than $65 \%$ of the users at each urban park, perceive the pathways as safe under the current illumination. Less than $35 \%$ of the users at each of the four parks are satisfied with the quality of the current artificial lighting of pathways, suggesting that it is at a considerably low level. However, more than $50 \%$ of the users at each park, are satisfied with the impact the lighting designs have on their emotional state and restorative experience and believe that it creates a sense of place.

The findings of this study indicate that the existing light levels (perceived by the users as brightness) of pathways at all four urban parks are insufficient. It has affected the park users' perception of safety, and together with the poor selection and placement of lamps and luminaires negatively have affected the overall quality of the lighting design. However, the CCT of the light sources used, was found to be positively affecting the users and is therefore preferred by many. The percentage of users who perceive the pathways as safe for use, is higher than those who prefer the existing brightness level at each urban park. This indicates that the users' perception of safety does not solely depend on the visibility created by artificial lighting. The users' familiarization with the park and its surrounding due to frequent visits, was identified as a prominent factor which influences the users' preference for brightness and perception of safety, despite the low illumination levels.

It is evident that the park users' preferences for artificial lighting of pathways: brightness, CCT, and Luminaire type and design are affected by their perceived safety, perceived lighting quality and the effect artificial lighting has on their emotional state and restorative experience. Therefore, these factors should be carefully considered when lighting up pathways in urban parks to achieve a successful lighting design and thereby further enhance the users' nighttime experience at the park

\section{Conclusion and Recommendations}

The findings of this study indicate that the user preferences for artificial lighting are closely linked to their perception of the lit environment. The users' perception of safety, perception of lighting quality, and the impact of lighting on their emotional state and restorative experience was found to affect their preferences 
related to brightness and CCT of the light sources, as well as the preference for the luminaire type and design.

The horizontal illumination level of pathways at all four urban parks selected for this study was below 10 lux, considerably lower than the standard minimum horizontal illumination level (50 lux) recommended by the IESNA. The insufficient lighting levels have contributed towards the reduction of perceived safety, which in turn has negatively affected the users' preference for the existing brightness levels. However, the study has also confirmed that the users' perception of safety is not solely dependent on artificial lighting: visibility (Rea, 2000), attention (Lindh, 2012), reassurance (Fotios, Unwin \& Farrall, 2014), facial/ emotional recognition (Fotios, Yang \& Cheal, 2013), obstacle detection (Fotios \& Cheal, 2008), etc. As observed through this study, safety perception may have also been influenced by the users' familiarity with the space (developed due to frequent visits), presence of other users, as well as the nature of the space: comfort, definition (Rea, 2000), entrapment (Blobaum \& Hunecke, 2005), etc. Thus, this study further strengthens the fact that the safety and security of humans depend on both visual and psychological aspects.

As observed in all four urban parks, improper shielding and placement of luminaires have resulted in sending light to unwanted areas, while the use of low wattage lamps and improper maintenance of the light fixtures have also contributed towards reducing the quality of the lit environment. This has resulted in significantly low levels of preference towards the existing luminaire types and designs. All selected parks had utilized lamps with warm white colour temperatures $(200 \mathrm{~K}-3500 \mathrm{~K})$, which creates a calm and relaxing ambience. The positive effect on the users' emotional state and restorative experience has induced a higher preference towards the CCT of the light sources. Thus, this study substantiates the findings of Veitch \& Newsham (1996), who highlight the importance of several parameters of the lit environment including illuminance, glare, and SPD, and state that they affect the users' behavioural outcomes such as visual performance, post-visual performance, health and safety, social interaction, mood states (happiness, alertness, satisfaction and preference), and aesthetic judgements.

According to observations, the pathways selected for the study in all four urban parks are being utilized by their users. However, based on the questionnaire survey, majority of the users are not satisfied with the overall pathway lighting design. According to the Information Processing Theory (Kaplan \& Kaplan, 1989), this indicates that the artificial lighting of these pathways provides Coherence and Legibility, which facilitates environmental perception and in turn the use of the pathways, but lacks in Complexity and Mystery, and thereby limits exploration and reduces user preference levels. If placed within the Hierarchy of Walking Needs (Alfonzo, 2005), the current pathway lighting of all four urban parks provide for the users' most basic need (that can be fulfilled by the urban form/ infrastructure) - Accessibility, but lack in the provision of user Comfort, Safety, and Pleasure.

Majority of the park users' overall night time experience was found to be average, providing a direct link between the shortcomings of the lighting design and the user experience. Therefore, it is evident that the careful consideration and integration of user preferences can help in achieving a successful lighting design, which contributes towards further enhancing the night time experience of all urban park users.

This study was limited to the evaluation of user preference related to three artificial lighting parameters: brightness, CCT, and luminaire type/ design, whereas the reasons for preference were evaluated under three overarching themes: perceived safety, perceived lighting quality, and restorative experience. Therefore, it is important to conduct further research on user perceptions and preferences related to various parameters of artificial lighting: resource/ task/ eye geometry, shadows, peripheral detection etc., that are considered important in terms of pathway lighting. Due to the constant exposure to poor lighting conditions and the involuntary nature of the human visual process, people do not often consciously understand the implications of poor lighting designs, unless they get a chance for comparison or are knowledgeable on the subject matter. Therefore, if possible, it is better if further research offers the participants a chance for direct comparison between varying degrees of the respective parameter within the same context.

\section{References}

Abkar, M., Mustafa, K. M., Maulan, S., \& Davoodi, S. R. (2011). Determining the visual preference of urban landscapes. Scientific Research and Essays, 6(9), 1991-1997. doi:10.5897/SRE11.171

Alfonzo, M. A. (2005). To walk or not to walk? The hierarchy of walking needs. Environment and Behaviour, 37(6). 
doi:10.1177/0013916504274016

Allan, A. C., Hansen, V. G., Isoardi, G., \& Smith, S. S. (2019). Subjective assessments of lighting quality: a measurement review. LEUKOS The Journal of the Illuminating Engineering Society, 15(2-3).

doi:10.1080/15502724.2018.1531017

Blobaum, A., \& Hunecke, M. (2005). Perceived danger in urban public space: the impacts of physical features and personal factors. Environment and Behaviour, 37(4), 465-486. doi:10.1177/0013916504269643

Dugar, A. M. (2011). Lighting urban parks - reviewing the basics. Lighting Research and Design, 40-42.

Ernawati, J., Surjono, S., \& Sudarmo, B. S. (2018). People's preferences of urban design qualities for walking on a commercial street. IOP Conference Series Earth and Environmental Science, 126. doi:10.1088/1755$1315 / 126 / 1 / 012206$

Fotios, S. A., \& Cheal, C. (2008). Obstacle detection: a pilot study investigating the effects of lamp type, illuminance, and age. Lighting Reasearch and Technology, 41(4), 321-342. doi:10.1177/1477153509102343

Fotios, S. A., \& Cheal, C. (2010). Brightness matching with visual fields of different types. Lighting Research and Technology, 43, 73-85. doi:10.1177/1477153510369478

Fotios, S. A., Yang, B., \& Cheal, C. (2013). Effects of outdoor lighting on judgements of emotion and gaze direction. Lighting Research and Technology, 47(3), 301-315. doi:10.1177/1477153513510311

Fotios, S., Unwin, J., \& Farrall, S. (2014). Road lighting and pedestrian reassurance after dark: a review. Lighting Research and Technology, 47(4), 449-469. doi:10.1177/1477153514524587

Gibson, J. J. (1977). The theory of affordances. In R. Shaw, \& J. Bransford, Percieving, acting, and knowing: toward an ecological psychology (pp. 67-82). Mahwah, NJ: Lawrencw Erlbaum.

Heijgen, E. v. (2013). Human landscape perception. UK: Wageningen University.

Johansson, M., Rosen, M., \& Kuller, R. (2010). Individual factors influencing the assessment of the outdoor lighting of an urban footpath. Lighting Research and Technology, 42(1). doi:10.1177/1477153510370757

Kaplan, R., \& Kaplan, S. (1989). The experience of nature: a psychological perspective. Cambridge, New York: Cambridge University Press. Retrieved from https://archive.org/details/experienceofnatu00kapl

Kaplan, S. (1975). An informal model for the prediction of preference. In E. H. Zube, R. O. Brush, \& J. G. Fabos, Landscape assessment: values, perception and resources (pp. 92-101). Stroudsburg, PA: Dowden. Hutchinson and Ross.

Knight, C. (2010). Field surveys of the effect of lamp spectrum on the perception of safety and comfort at night. Lighting Research and Technology, 42, 313-329.

Lindh, U. W. (2012). Light shapes spaces: experience of distribution of light and visual spatial boundaries. Sweden: ArtMonitor, Faculty of Fine, Applied and Performing Arts, University of Gothenburg.

Luo, W., Puolakka, M., Qingwen, Z., \& Chunyu, Y. (2013). Pedestrian way lighting: user preferences and eyefixation measurements. Illumination Engineering, 15(1), 19-34.

Manning, R., Rovelstad, E., Moore, C., Hallo, J., \& Smith, B. (2016). Indicators and standards of quality for viewing the night sky in the national parks. Park Science, 32(1). doi:10.3390/su12041330

Maslow, A. H. (1954). Motivation and personality. New York: Harper \& Brothers.

National Park Service. (2006). Management Policies. Denver, CO: U. S. Department of the Interior. Retrieved from http://www.nps.gov/policy/mp2006.pdf

Navvab, M. (2002). Visual acuity depends on the color temperature of the surround lighting. LEUKOS The Journal of the Illuminating Engineering Society of North America, 31(1), 70-84. doi:10.1080/00994480.2002.10748373

Nikunen, H., \& Korpela, K. (2009). Restorative lighting environments: does the focus of light have an effect on restorative experiences? Journal of Light and Visual Environment, 33(1). doi:10.2150/JLVE.33.37

Patching, G. R., Rahm, J., Jansson, M., \& Johansson, M. (2017). A new method of random environmental walking for assessing behavioural preferences for different lighting applications. Frontiers in Psychology, 8, 345. doi:10.3389/fpsyg.2017.00345

Prachi, P., \& Krzysztof, S. (2020). A multi-criteria assessment procedure for outdoor lighting at the design stage. Sustainability, 12(4), 1330. doi:10.3390/su12041330

Rahm, J., \& Johansson, M. (2016). Walking after dark - a systematic literature review of pedestrians' response to outdoor. Environmental Psychology Monographs, 26.

Rahm, J., \& Johansson, M. (2018). Assessing the pedestrian response to urban outdoor lighting: a full-scale laboratory study. PLoS ONE, 13(10). doi: 10.1371/journal.pone.0204638

RASC. (2018). Guidelines for outdoor lighting (low impact lighting). Royal Astronomical Society of Canada, RASC Dark Sky Protection Programs.

Rea, M. S. (2000). The IESNA lighting handbook (9th ed.). Illuminating Engineering Society of North America.

Rea, M. S., Bullough, J. D., \& Akashi, Y. (2009). Several views of metal halide and high-pressure sodium lighting for outdoor applications. Lighting Research and Technology, 41(4). doi:10.1177/1477153509102342

Richardson, E. A., Mitchell, R., Hartig, T., de Vries, S., Astell-Burt, T., \& Frumkin, H. (2012). Green cities and health: a question of scale? J Epidemiol Community Health, 66(2), 160-5. doi:10.1136/jech.2011.137240 
Schiffman, H. R. (2000). Sensation and perception: An integrated approach (5th ed.). New Yprk, NY: John Wiley and Sons Inc.

Silva, A. K. (2011). The importance of effective lighting in landscape design. Faculty of Architecture, University of Moratuwa.

Smith, B., \& Hallo, J. (2019). Informing good lighting in parks through visitors' perceptions and experiences. International Journal of Sustainable Lighting, 47-65. doi:10.26607/ijsl.v21i02.93

Unver, A. (2009, February). People's experience of urban lighting in public space. Department of City and Regional Planning, Middle East Technical University.

Veitch, J. A., \& Newsham, G. R. (1996). Determinants of lighting quality II: research and recommendations. Lighting Research and Recommendations. Toronto: National Research Council of Canada.

Zhai, Y., \& Baran, P. K. (2016). Urban park pathway design characteristics and seniors' walking behavior. Urban Forestry and Urban Greenery, 21, 60-73. doi: 10.1016/j.ufug.2016.10.012 